\title{
OFERTA DE MASSIVE OPEN ONLINE COURSES - MOOCS NO BRASIL: OPORTUNIDADES DE FORMAÇÃO EM CENÁRIOS DE INCERTEZA
}

\author{
GOMES, Yasmim Terezinha Barbosa ${ }^{1}$ \\ PINHEIRO, Julia Lorena Gonçalves ${ }^{2}$ \\ ROCHA, Amanda Tineli ${ }^{3}$ \\ SOARES, Simarly Maria ${ }^{4}$
}

VIEIRA, Rafaella Costa Fagundes ${ }^{5}$

Recebido em: 2020.09.10 Aprovado em: 2021.04.27 ISSUE DOI: $10.3738 / 1982.2278 .3841$

RESUMO: A tecnologia e a internet possibilitam a disseminação do conhecimento com a aprendizagem online. A disponibilidade de acesso em qualquer hora e lugar é válida na busca por aprimoramento, tanto para o desenvolvimento profissional quanto pessoal. Se esse desenvolvimento advém de forma gratuita e com poucos requisitos de pré-qualificação, é ainda mais proveitoso. Os cursos na modalidade Massive Open Online Courses (MOOCs) atendem a essa demanda com a oferta de cursos gratuitos para público com diversidade de idade e formação. Nesse sentido, este artigo possui como objetivo caracterizar o panorama de oferta de MOOCs no Brasil. Por meio de pesquisa documental, foram identificados 724 cursos das diversas áreas do conhecimento, com sugestão de público-alvo desde o ensino fundamental até o nível superior. Os resultados apontam instituições, área de conhecimento, carga horária, pré-requisitos e tempo de realização dos cursos. Este trabalho contribui para a expansão do uso das plataformas como recurso para aqueles que desejam ampliar seus conhecimentos e certificação.

Palavras chave: Educação à distância. Cursos. Desenvolvimento Profissional.

\section{OFFER OF MASSIVE OPEN ONLINE COURSES - MOOCS IN BRAZIL: TRAINING OPPORTUNITIES IN UNCERTAINTY SCENARIOS}

\begin{abstract}
SUMMARY: Technology and the internet enable the dissemination of knowledge through online learning. The availability of access at any time and place is valid in the search for improvement, both for professional and personal development. If this development comes free of charge and with few pre-qualification requirements, it is even more beneficial. Massive Open Online Courses (MOOCs) courses meet this demand with the offer of free courses for audiences of different ages and backgrounds. In this sense, this article aims to characterize the panorama of the offer of MOOCs in Brazil. Through documentary research, 724 courses from different areas of knowledge were identified, with the suggestion of a target audience from elementary school to higher education. The results point to institutions, knowledge area, workload, prerequisites and duration of the courses. This work contributes to the expansion of the use of platforms as a resource for those who wish to expand their knowledge and certification.
\end{abstract}

Keywords: Distance education. Courses. Professional development.

\section{INTRODUÇÃO}

A tecnologia ocupa cada vez mais espaço na rotina dos indivíduos com as diversas formas de interação entre sujeitos, principalmente com o uso da internet. A educação à distância destaca-

\footnotetext{
${ }^{1}$ Bacharelanda em Administração pela Universidade Estadual de Montes Claros.

${ }^{2}$ Bacharelanda em Administração pela Universidade Estadual de Montes Claros.

${ }^{3}$ Bacharelanda em Administração pela Universidade Estadual de Montes Claros.

${ }^{4}$ Doutora em Administração pela Universidade de Brasília.

${ }^{5}$ Bacharelanda em Administração pela Universidade Estadual de Montes Claros.
} 
se como uma forma de aprendizagem que possibilita o acesso mais amplo ao conhecimento. Para fins deste estudo evidencia-se o uso de ambientes virtuais, tais como os Massive Open Online Courses (MOOCs), acrônimo inglês para cursos online abertos ao público (CARMO et al, 2019).

Seja estudante de nível fundamental, médio, universitário, profissional desempregado, empregado buscando qualificação, ou até mesmo, empresas buscando capacitar seus colaboradores, é necessário apenas o acesso à internet para se beneficiar de cursos disponibilizados em plataformas de renome.

A Organização Mundial da Saúde - OMS por meio de coletiva de imprensa comandada pelo Diretor Geral Tedros Ghebreyesus, declarou no dia 30 de janeiro de 2020, o surto de Covid19 como uma emergência de saúde a nível internacional (G1, 2020). A pandemia fez valer diversas medidas para contenção, dentre elas o isolamento social, indicado pela OMS como melhor forma de reduzir sua transmissão. O Governo Federal, diante a situação, instituiu a Lei Federal n ${ }^{\circ}$ 13.979, de 6 de fevereiro de 2020, que disserta sobre diversas ações em relação às compras, importações e, principalmente, as medidas de contenção social, como o isolamento e quarentena. Diante esse novo cenário, as pessoas tiveram de se reinventar devido a restrições advindas da situação de pandemia, tendo que se adaptar à rotina domiciliar e fazer melhor uso do tempo.

Segundo o estudo realizado pela Fundação Getúlio Vargas (FGV, 2020), o Indicador Coincidente de Desemprego (ICD), subiu 0,6 pontos em março. A instituição afirma que ainda não há impacto deste indicador em março, mês da coleta de dados, no entanto, é possível supor uma piora do indicador para os próximos meses. Sem a possibilidade de sair de casa e tendo previsões de um mercado incerto após o retorno às tarefas habituais, a capacitação à distância com os MOOCs, têm se mostrado uma boa oportunidade para qualificação rápida para quem deseja se manter ou reinserir-se no mercado de trabalho.

Com base no contexto apresentado, tem-se como objetivo caracterizar o panorama de oferta de MOOCs no Brasil, relacionando algumas instituições que ofertam, segmento do curso, entre outras informações de livre acesso.

\section{REFERENCIAL TEÓRICO}

\subsection{Educação a distância - EAD}

A Educação a distância - EAD, pode ser definida, segundo o art. $1^{\circ}$ do Decreto $n^{\circ} 9.057$, de 25 de maio de 2017, como: "modalidade educacional na qual a mediação didático-pedagógica nos processos de ensino e aprendizagem ocorra com a utilização de meios e tecnologias de 
informação e comunicação [...]" (BRASIL, 2017). A ideia central do EAD é o compartilhamento de conhecimento em lugares distintos e tempos diferentes.

O Sindicato das Entidades Mantenedoras de estabelecimentos de Ensino Superior SEMESP apresentaram dados que evidenciam que a educação a distância é um modelo de ensino em expansão nacional e mundial, devido, principalmente, à facilidade de adaptação e inovação que as ferramentas tecnológicas fornecem (MELO; OLIVEIRA, 2019). O perfil do público que já é usuário desta modalidade de ensino pode ser caracterizado como pessoas ativas que têm que conciliar diversos afazeres paralelos à educação, que impedem ou limitam a educação tradicional, ou pessoas com restrição logística ao ensino presencial (RAMOS; RIBEIRO, 2019).

Por sua vez, os MOOCs exigem um design instrucional adaptados aos diferentes tipos de necessidades dos usuários. Nesse sentido, a percepção dos aprendizes como reação positiva aos procedimentos instrucionais é um preditor significativo do processo de aprendizagem (SOUZA; ZERBINI, 2019). A avaliação dos cursos na modalidade à distância demonstra que há efetividade de resultados positivos tanto no nível de desempenho no trabalho quanto para o desenvolvimento pessoal (MOURÃO et al., 2013).

A atualização rápida das informações dos cursos gera nos alunos a reação positiva de que estão aprendendo (SOUZA; ZERBINI, 2019). Complementarmente, egressos de curso à distância percebem o impacto positivo em suas atividades laborais, quando submetidos a ações educacionais que foram concebidas com escolha criteriosa dos conteúdos e explanação das contribuições que o treinamento oferece ao indivíduo e ao mercado profissional. E ainda, quando tiveram apoio dos gestores e colegas para aplicar no trabalho o que foi aprendido no curso (MOURÃO et al., 2013).

Apesar de oferecer qualificação e facilidade de acesso em termos de tempo e localização (RAMOS; RIBEIRO, 2019; MOURÃO et al., 2013), há alta evasão nesta modalidade de ensino, inclusive nos MOOCs (SOUZA; ZERBINI, 2019). Sobretudo, em situações atípicas como a pandemia do vírus Covid-19, que tem mantido os profissionais em isolamento social, a alternativa para o ensino a distância possibilita o acesso à aprendizagem, com diversas opções e áreas de conhecimento mediado pela internet. Inclusive, cursos em plataformas gratuitas, como é o caso dos MOOCs.

\subsection{Massive Open Online Courses - MOOCs}

O surgimento dos MOOCs se relaciona com a experiência de George Siemens e Stephen Downes, na University of Manitoba, no Canadá em 2008, quando criaram um curso intitulado 
Connectivism and connective knowledge com o objetivo de apresentar uma nova teoria de aprendizagem denominada Conectivismo (MARTINS et al. 2017). Nos anos seguintes várias universidades de todo o mundo geraram mecanismos semelhantes. O crescimento dos MOOCs é uma tendência observada mundialmente (MOTA; SANTOS, 2012).

Segundo Dal Forno e Knoll (2013), os MOOCs são uma modalidade que compreende o ensino de longa escala e de forma gratuita. Esses cursos livres são oferecidos por plataformas com uso de conexão em rede de internet (online), não há necessidade de se estar matriculado em uma instituição de ensino convencional, apenas é preciso realizar inscrição na plataforma de maneira aberta (open) e estão disponíveis para uma grande quantidade de pessoas atingindo o público massivo (massive). Como afirma Dal Forno e Knoll (2013), a realização do curso não se sujeita a um critério específico de seleção, entretanto pode se fazer necessário algum determinado conhecimento prévio.

Os MOOCs são cursos de períodos curtos, promovidos e coordenados por universidades e instituições do segmento educacional e disponibilizados em plataformas virtuais específicas. Conforme Fassbinder (2017), as plataformas de MOOC se estruturam em qualquer ambiente em que haja as ferramentas adequadas para sua criação, tais plataformas são conhecidas como Massive Open Online Education Platform (MOOEP), como também se entende que provedor de MOOCs ou MOOCs Delivery Platform corresponde a qualquer entidade ou ambiente que disponibiliza um MOOC para um grupo de participantes. Dal Forno e Knoll (2013), apontam que as plataformas mais conhecidas, atribuem-se a Coursera, edX e Udacity, dos Estados Unidos, Future Learn, do Reino Unido, e a europeia OpenupEd.

De acordo com Barin e Bastos (2013), os modelos de MOOCs mais costumeiros são os XMOOCs, que mais se assemelham às tradicionais aulas presenciais, nos quais a figura do professor ainda exerce o papel central e os c-MOOCs, nos quais os próprios alunos geram a maioria das atividades, escrevendo suas próprias reflexões em blogs e plataformas sociais e compartilhando com seus pares. Os modelos X-MOOCs são, segundo Dal Forno e Knoll (2013), uma extensão dos modelos pedagógicos utilizados pelas instituições de ensino tradicionais, entretanto, mantém padrões instrucionais de ensino, ou seja, fazendo uso do design instrucional. Como semelhança, esses modelos apresentam características voltadas à recursos multimídia, número expressivo de participantes e conteúdo semanal (FASSBINDER; DELAMARO; BARBOSA, 2017).

A compreensão acerca dos MOOCs perpassa pelos aspectos de desterritorialização da educação e se configuram no contexto de permitir às pessoas o acesso às instituiçõos de ensino que não seria possível de forma presencial, podendo fornecer capacitação e formação (DAL 
FORNO; KNOLL, 2013). Para os usuários, os MOOCs permitem a aprendizagem com flexibilidade de horário, utilização de materiais educacionais de qualidade no ambiente virtual, além de estabelecer um canal de comunicação para pessoas que possuem interesses semelhantes (MACHADO, 2019).

Os estudos sobre MOOCs no Brasil são recentes, pouco consolidados e apresentam demandas por novas pesquisas (CARMO et al. 2019). Conforme Moura e Souza (2017) a maioria dos cursos não exige pré-requisitos, são lecionados no idioma português, concentram-se em algumas áreas do conhecimento, mais da metade dos cursos permitem inscrições imediatas e não oferecem certificação. O estudo de Dal Forno e Knoll (2013), analisou as plataformas edX e OpenupEd e verificou que há certa homogeneidade nos cursos ofertados pela plataforma edX, especialmente em relação ao idioma e aos formatos empregados, o que pode ser explicado pela presença majoritária de instituições norte-americanas na plataforma. Enquanto na plataforma OpenupEd foi constatada maior diversidade tanto nos idiomas, quanto nos formatos dos cursos.

\section{MÉTODO}

Esta pesquisa trata-se de um estudo descritivo com abordagem qualitativa, que utilizou a pesquisa documental sobre MOOCs oferecidos por instituições brasileiras. Os dados dos cursos disponíveis nos sites das instituições que ofertam MOOCs foram analisados e categorizados.

O Ministério da Educação (MEC) foi a referencia para buscar as informações acerca de cursos ofertados a distância no Brasil. O MEC disponibiliza em seu site (portal.mec.gov.br), vagas de cursos online abertos gratuitos em plataformas MOOCs com opções em diferentes áreas do conhecimento. Eles são acessíveis a qualquer indivíduo que tenha conexão com a internet. No site constam Institutos Federais que oferecem MOOCs, sendo eles: Instituto Federal Baiano (IFBaiano), Instituto Federal Sertão Pernambucano (IFSertãoPE), Instituto Federal do Acre (IFAC), Instituto Federal do Amazonas (IFAM), Instituto Federal do Pará (IFPA), Instituto Federal de Rondônia (IFRO), Instituto Federal do Tocantins (IFTO), Instituto Federal do Espírito Santo (IFES), Instituto Federal do Sul de Minas Gerais (IFSuldeMinas), Instituto Federal do Rio de Janeiro (IFRJ), e o Instituto Federal do Rio Grande do Sul (IFRS).

Devido à acessibilidade aos dados referentes aos cursos, outras instituições foram utilizadas na amostra, sendo essas instituições: Serviço Brasileiro de Apoio às Micro e Pequenas Empresas (Sebrae), Fundação Bradesco, a Escola Virtual do Governo (EV.G), e FGV. Por ser uma ferramenta aberta, sem um local que contemple todos os dados, foi feito um levantamento amostral por conveniência. 
$\mathrm{Na}$ análise documental houve a participação de cinco pesquisadores, cada um acessou uma plataforma e relacionou as seguintes categorias: instituições credenciadas; segmento dos cursos ofertados; carga horária; público-alvo; idioma; requisitos; prazo de acesso; avaliação do aluno; oferecimento de certificação (mediante pagamento ou gratuitamente) ou não.

Para analisar os dados das categorias selecionadas, usou-se a análise de conteúdo de Bardin (1979), que a define como uma técnica de investigação que tem por finalidade a descrição objetiva, sistemática e quantitativa do conteúdo manifesto da comunicação. Definiu-se as categorias importantes que facilitam o interesse das pessoas pelos MOOCs.

\section{RESULTADO E DISCUSSÃO}

Esta seção apresenta a oferta dos MOOCs com base nas consultas aos dados dispostos nos sites institucionais das plataformas que oferecem tais cursos. Das plataformas utilizadas que se caracterizam como MOOCs foram selecionados os Institutos Federais (IFRS, IFRJ, IFBaiano, IFSuldeMinas, IFES, IFSertãoPE, IFAM, IFAC, IFPA, IFRO e IFTO com o total de 303 cursos), Sebrae (116 cursos), Fundação Bradesco (90 cursos), EV.G (158 cursos) e FGV (57 cursos), totalizando 724 cursos.

Os cursos oferecidos são divididos em áreas como: administração pública, empreendedorismo, educação, finanças, marketing, ética e cidadania, gestão de pessoas, logística, idioma, informática e tecnologia, entre outros. Pode-se observar que a maioria dos cursos são voltados para a área de administração, gestão e empreendedorismo. Os cursos da plataforma Sebrae se destacam por apresentarem conteúdos basicamente direcionados para empreendedores e gestores de como abrir, gerir e manter o seu negócio. Enquanto isso, a EV.G também apresenta, em sua maioria, cursos direcionados a área da administração, porém são voltados para gestão pública.

A carga horária dos cursos está representada no Gráfico 1. O eixo horizontal representa a carga horária dos cursos e o eixo vertical expressa a quantidade de cursos que apresentam aquela carga horária, as barras demonstram a frequência de cada carga horária. Conforme pode ser observado, a duração dos cursos varia de 40 minutos a 250 horas. Sendo o curso com maior tempo de duração da EV.G, da área de Gestão de Políticas, com 250 horas, enquanto os de menor duração são da Fundação Bradesco com 5 cursos de 40 minutos cada. No geral, os cursos apresentam, em média, 40 horas. Cerca de 234 dos 724 cursos analisados apresentaram essa carga horária, logo atrás ficam os 96 cursos de 20 horas de duração. Em 5 dos cursos analisados não foram informados o tempo de duração. 
Gráfico 1: Carga horária

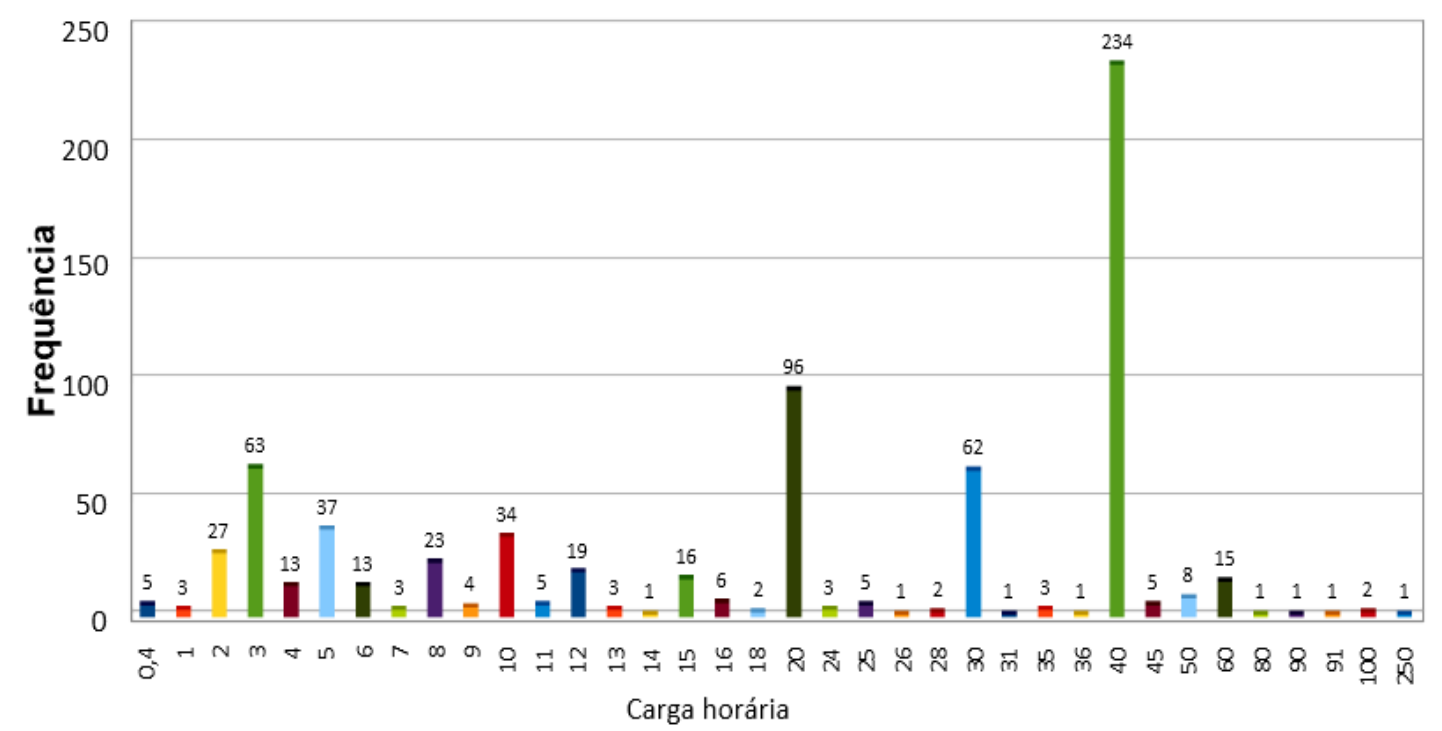

Fonte: Elaborado pelas autoras (2020).

De modo geral a EV.G é a plataforma que contêm os cursos com maior carga horária, com 56 cursos de 20 horas, 34 cursos de 40 horas e 25 cursos com 30 horas. Ou seja, os cursos possuem longa duração para o aperfeiçoamento pessoal. Já Moura e Souza (2017) ao discutirem características disruptivas dos MOOCs indicaram que 32,4\% dos cursos analisados apresentaram informações com relação a carga horária e desses, apenas 39,1\% possuíam mais de 20 horas.

No que diz respeito ao público-alvo, o Gráfico 2 demonstra que a maioria dos cursos é aberto ao público em geral interessado no assunto, sendo 262 cursos (aproximadamente 36\%) do total. Não foram informados o grupo-alvo de 116 cursos (16\%). Servidores e agentes públicos ficaram em segundo lugar com aproximadamente $16 \%$ e em terceiro, os cursos cujo alvo são estudantes, professores e profissionais que atuam na área, com 56 cursos (8\%) disponibilizados. 
Gráfico 2: Público-alvo de oferta dos MOOCs

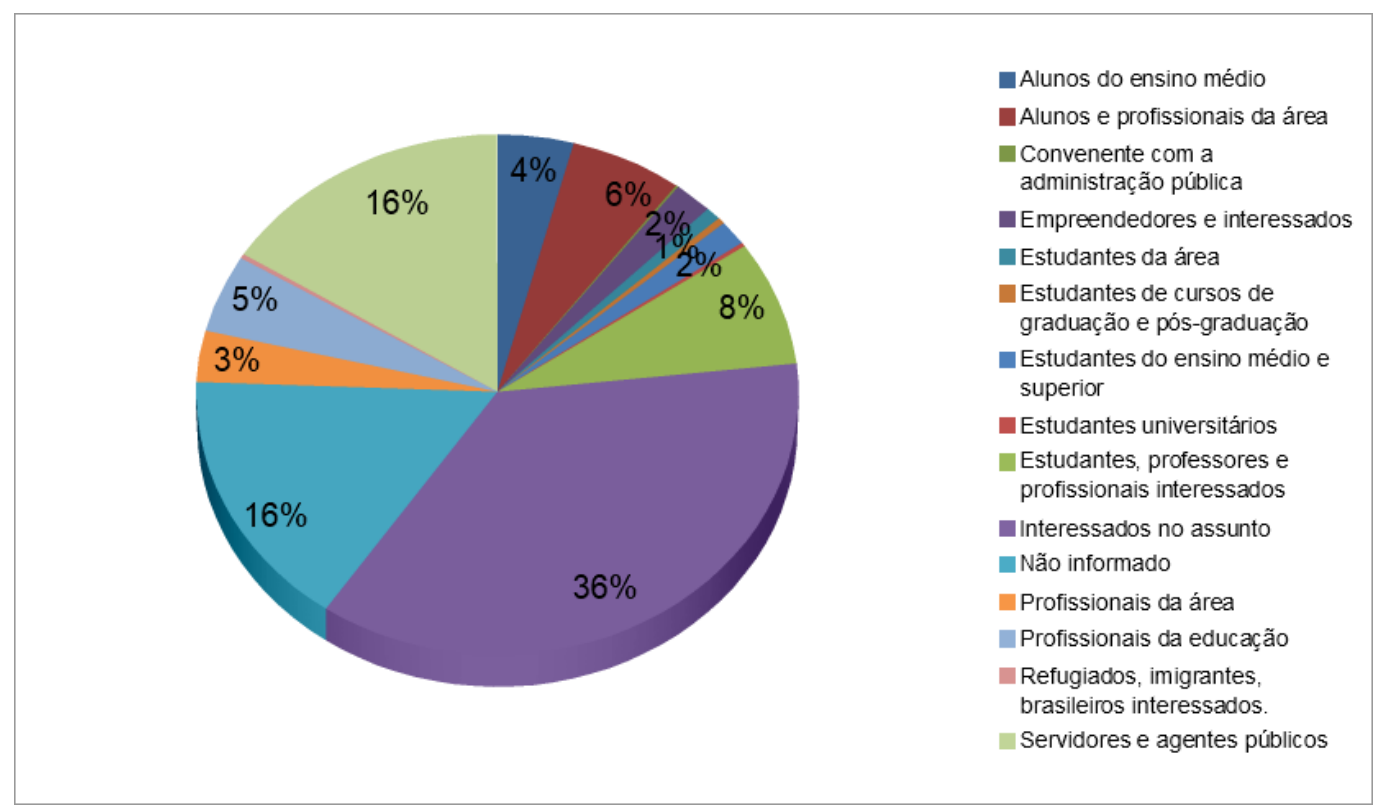

Fonte: Elaborado pelas autoras (2020).

A análise do público-alvo por plataforma, indica que os cursos da EV.G são majoritariamente focados em servidores, agentes, convenentes e gestores públicos, $73 \%$ de acordo com o Gráfico 3.

Gráfico 3: Público-alvo EV.G

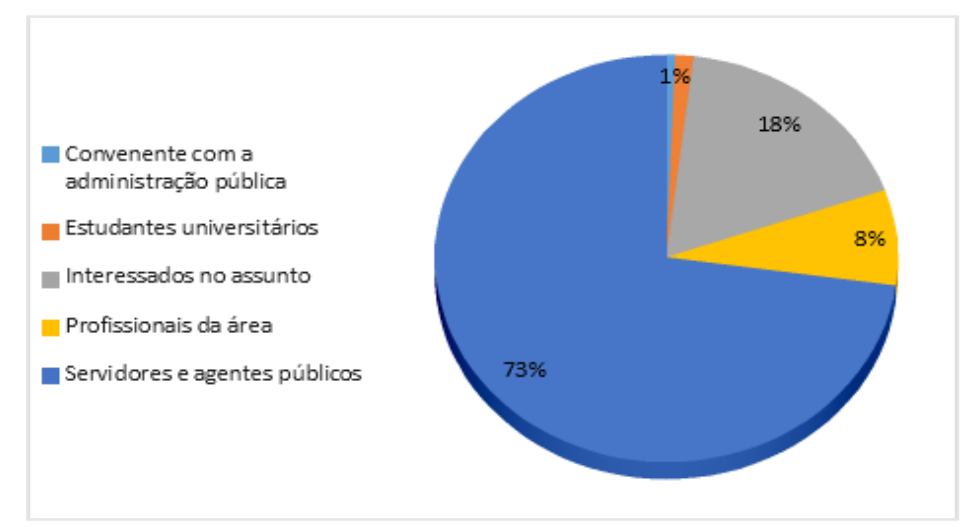

Fonte: Elaborado pelas autoras (2020).

Os cursos dos Institutos Federais e da FGV, Gráfico 4, são orientados a interessados no assunto (40\%) e estudantes principalmente do ensino médio e professores (16\%). Já os cursos da Fundação Bradesco são de livre acesso, sem direcionamento de público-alvo. E por fim, os cursos do Sebrae que apesar de não informarem o público-alvo, nota-se pelo conteúdo que são direcionados para empreendedores, pessoas que pensam em montar ou já possuem o próprio negócio. 
Gráfico 4: Público-alvo IFs e FGV

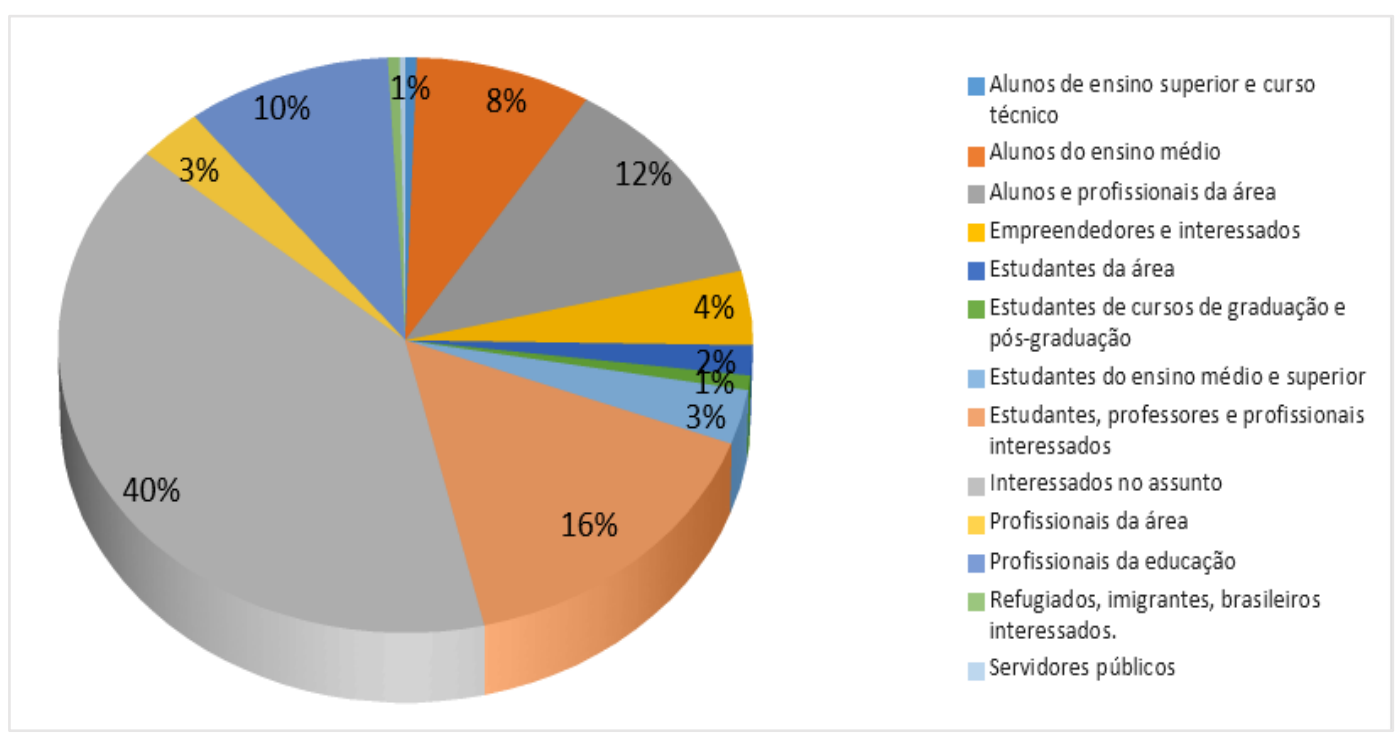

Fonte: Elaborado pelas autoras (2020).

Os MOOCs, em instituições brasileiras oferecem os cursos majoritariamente em português, mas vale destacar que o ensino também é ofertado em outros idiomas. A disponibilidade de outras linguagens nos cursos se concentra em Institutos Federais, de modo que não há grande variedade utilizando somente o idioma inglês e espanhol. Dois cursos são acessíveis em inglês e oito são disponibilizados em português e inglês. Outra categoria identificada se relaciona a cursos de língua inglesa, mas estão em português uma vez que em seu conteúdo programático se utiliza textos e termos em inglês. Em relação ao idioma espanhol, três cursos nesta linguagem que também podem ser realizados em português, conforme é evidenciado na Tabela 1.

Moura e Souza (2017) identificaram que 97,2\% dos cursos analisados eram aplicados no idioma português, percentual próximo ao atingido neste estudo, que identificou 97,6\% dos cursos na língua portuguesa. Já os resultados do estudo de Dal Forno e Knoll (2013), demonstraram que os cursos disponibilizados na plataforma $e d X$, eram produzidos na língua inglesa incluindo os cursos de outras nacionalidades, enquanto que a plataforma OpenupEd, possuía cursos de 12 idiomas diferentes, sendo os de maior ocorrência: o italiano, (já que a Itália possuía o maior número de cursos ofertados na plataforma), o inglês, o árabe, o espanhol e o francês.

Não foram encontrados estudos recentes que relatem o panorama atual dos idiomas ofertados pelas plataformas citadas por Dal Forno e Knoll, no entanto em consulta realizada na 
plataforma $e d X$ (2021) foi identificado que há oferta de mais de 20 idiomas sendo os principais inglês com 2885 cursos, espanhol com 497 e francês com 82. Não foram localizadas tais informações de fácil acesso na plataforma OpenupEd, portanto sugere-se pesquisa que revele se houve queda ou acréscimo das línguas disponibilizadas nos últimos anos.

A seguir, é apresentada a Tabela 1, que contém os idiomas e frequência identificados nos cursos analisados.

Tabela 1: Idioma

\begin{tabular}{c|c}
\hline Idioma & Frequência \\
\hline Inglês & 2 \\
\hline Português & 707 \\
\hline Português (contém termos e textos em inglês) & 4 \\
\hline Português e espanhol & 3 \\
\hline Português e inglês & 8 \\
\hline Total geral & 724 \\
\hline
\end{tabular}

Fonte: Elaborado pelas autoras (2020).

No tocante aos requisitos, de modo amplo, os MOOCs em diferentes plataformas não exigem que os inscritos detenham algum nível de conhecimento prévio ou formação para realizar o curso, como descrito nos resultados do estudo de Moura e Souza (2017) que apontaram que $80,3 \%$ dos cursos analisados pelos autores não solicitavam nenhum pré-requisito.

O Gráfico 5 mostra que 409 (aproximadamente 57\%) do total de cursos não possui nenhum requisito para que possa ser realizado. Enquanto 249 (aproximadamente 35\%) dos cursos exigem que o indivíduo seja estudante, tenha algum conhecimento prévio e talvez algum recurso/ferramenta. Outro requisito é ser servidor, agente, convenente ou gestor público (requisito em especial dos cursos da EV.G) total de 30 (4\%) cursos com esse requisito. Para instituições como a FGV e SEBRAE não há quaisquer tipo de exigência para a realização dos cursos. Alguns cursos da Fundação Bradesco, apesar de não terem um pré-requisito, recomendam uma idade mínima para o participante. 
Gráfico 5: Requisitos das plataformas

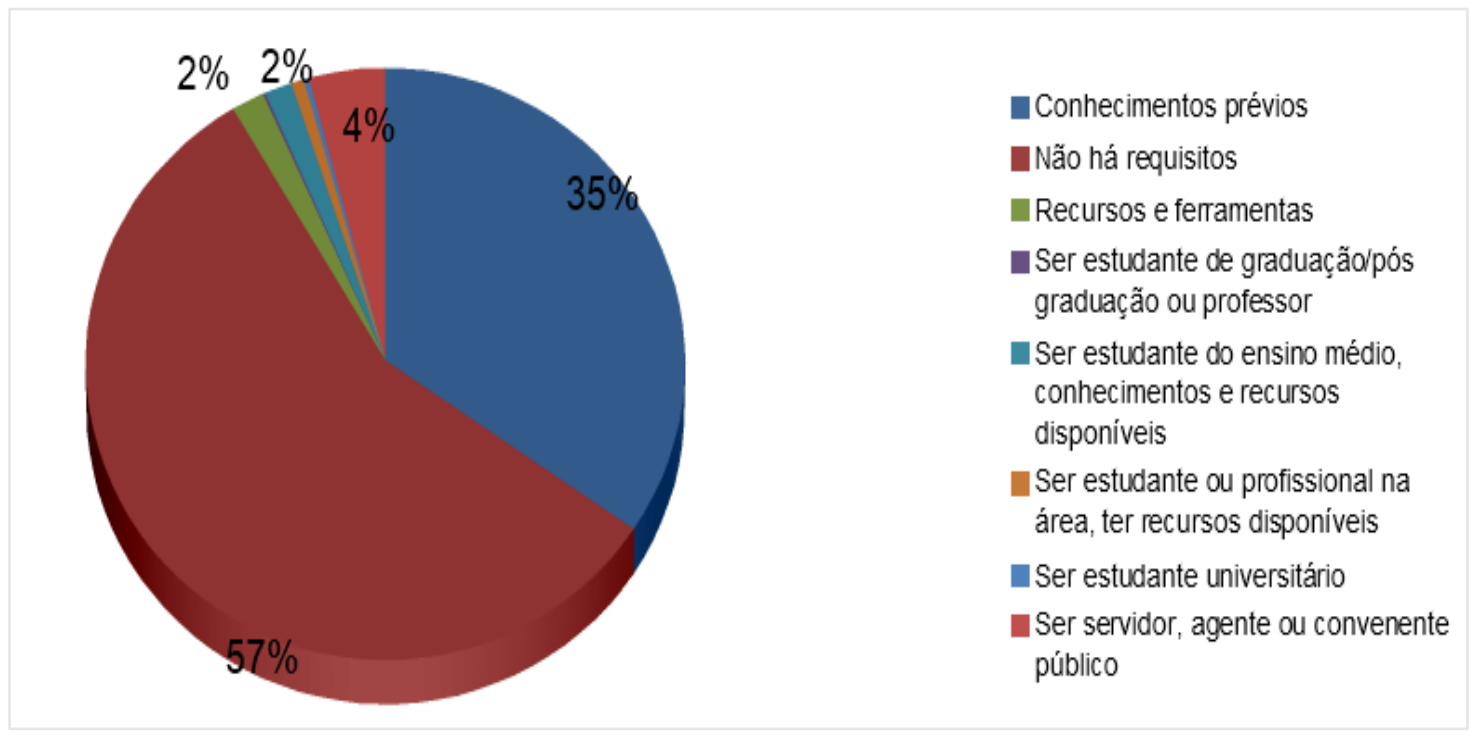

Fonte: Elaborado pelas autoras (2020).

Além de pré-requisitos, os MOOCs possuem determinado prazo de acesso a partir do momento em que fora realizada a inscrição, de tal modo, o ambiente virtual estará disponível somente neste período para o aluno acessar o material do curso. O tempo de duração dos acessos varia de 15 a 100 dias, sendo que a maior parte, correspondendo a 192 cursos, possuem 30 dias de duração. Em relação a outros cursos esta informação não está à disposição, pressupondo não haver restrições do período em que poderá ser realizado. É possível observar o detalhamento de disponibilidade das salas na Tabela 2.

Tabela 2: Sala disponível (Prazo de acesso ao curso)

\section{(Continua)}

\begin{tabular}{r|r}
\hline Sala disponível (dias) & Frequência (cursos) \\
\hline 15 & 111 \\
\hline 30 & 192 \\
\hline 40 & 33 \\
\hline 50 & 36 \\
\hline 60 & 92 \\
\hline 70 & 7 \\
\hline 90 & 6 \\
\hline
\end{tabular}


Tabela 2: Sala disponível (Prazo de acesso ao curso)

(Conclusão)

\begin{tabular}{r|c}
\hline Sala disponível (dias) & Frequência (cursos) \\
\hline 100 & 1 \\
\hline $\begin{array}{r}\text { Não } \\
\text { informado }\end{array}$ & 246 \\
\hline $\begin{array}{r}\text { Total } \\
\text { geral }\end{array}$ & 724 \\
\hline
\end{tabular}

Fonte: Elaborado pelas autoras (2020).

Ao que se refere a algum critério de avaliação para a conclusão do curso, dentre as instituições analisadas, identificou-se que 59\% dos cursos apresentam determinado tipo de avaliação, isso denota que para o término é necessário realizar algum teste de conhecimento do conteúdo estudado. Em $40 \%$ dos cursos não é informado de maneira prévia a necessidade de avaliação. Este percentual é relevante visto que é uma informação que deveria ser disponibilizada nas plataformas. Apenas $1 \%$ dos cursos utiliza o modelo de aplicação de quiz como método de teste de conhecimento de determinado assunto aprendido, conforme é possível visualizar no Gráfico 6.

Gráfico 6: Avaliação de aprendizagem

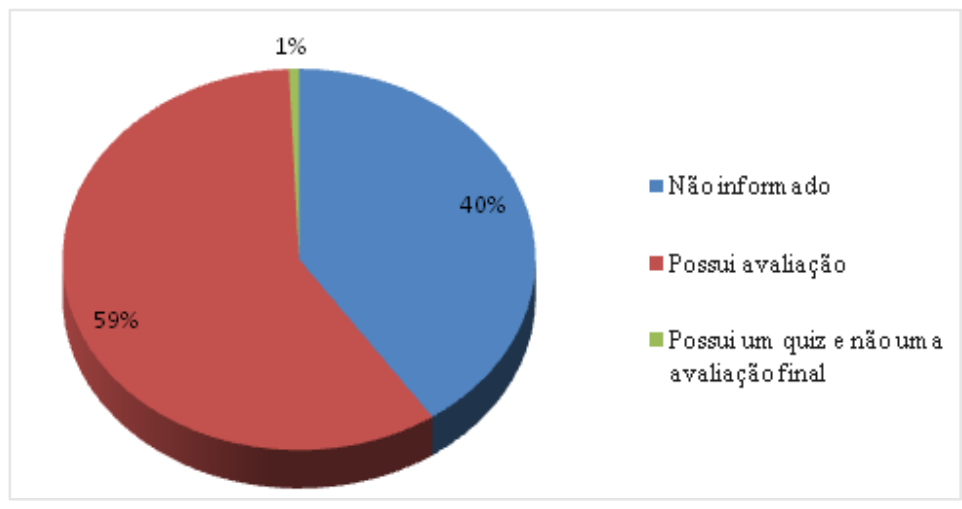

Fonte: Elaborado pelas autoras (2020).

Todas as instituições dispõem de certificação. A instituição que possui como critério a avaliação após o término do curso, concede a certificação mediante o desempenho mínimo obtido no teste. Do montante de 724 cursos totais, 421 (58\%) apresentam certificação, essa informação foi obtida na plataforma fornecedora do curso, enquanto 303 (42\%) dos cursos há certificação, com base em dados obtidos no portal do MEC. Os certificados de conclusão são digitais e emitidos gratuitamente para aluno aprovado. 
Segundo Moura e Souza (2017) 47,9\% dos MOOCs possuem certificação mediante pagamento de uma taxa de emissão média de $\mathrm{R} \$ 60,00$ e somente $11,3 \%$ oferecem certificado gratuito. Já Dal Forno e Knoll (2013), em seu artigo, demonstraram que na plataforma edX para a obtenção de certificado era necessário o pagamento de uma taxa mínima opcional de 50 dólares, porém a decisão de emissão e cobrança cabia à instituição coordenadora do curso. Ainda conforme as autoras, os resultados da análise da plataforma OpenupEd, indicaram que há cursos que oferecem certificado pago ou gratuito, com base em uma avaliação online, ou, em alguns casos, avaliação presencial realizada na instituição. Em consulta superficial às plataformas virtuais é perceptível que houve alteração do panorama de certificação apresentado em 2013 uma vez que os valores cobrados pela $e d X$ variam de curso para curso, e na OpenupEd não são apresentados valores, podendo indicar que só são informados ao final do curso, ou a certificação é gratuita.

Para a realização do estudo buscou-se analisar as informações que já estão divulgadas comumente nos canais de comunicação das plataformas ofertantes dos cursos. Encontrou-se escassez de determinados dados que seriam relevantes para o estudo, de maneira que se restringem a falta de resultados sobre os cursos ou ausência de divulgação, assim houve limitações no que se refere a dados precisos para o esclarecimento de elementos referentes ao perfil dos alunos que se cadastram nas plataformas seguindo faixa etária, escolaridade, gênero, como também o número percentual de inscritos e concluintes dos cursos. Tais informações auxiliam a produção do estudo com dados mais precisos para a formação de conhecimento sobre os MOOCs.

\section{CONSIDERAÇÕES FINAIS}

O objetivo do estudo foi atingido ao demonstrar que há oferta de MOOCs no Brasil, por diversas instituições, em diferentes áreas, e público-alvo variando desde estudantes a gestores.

Há vantagens e limitações acerca dos MOOCs. Dentre as vantagens, destaca-se o fácil acesso mediante o uso da internet e a diversidade de temas oferecidos, perante as limitações de ainda não ser difundido em grande escala no país.

Os MOOCs têm se desenvolvido não somente por uma tendência em educação, mas por uma demanda própria dos aprendizes que buscam alternativas como complemento a sua qualificação, o que é demonstrado principalmente na área de administração, que apresenta maior oferta de cursos. No âmbito nacional, essa modalidade evolui para a oferta de cursos sem prérequisitos disponíveis a quaisquer interessados. 
$\mathrm{O}$ rápido desenvolvimento tecnológico e o maior acesso à internet, têm provocado mudanças, facilitando e ampliando as oportunidades de aprendizagem, a qualquer tempo, em qualquer lugar. Conforme abordado neste estudo, os MOOCs têm sido difundidos como uma modalidade de educação aberta com cursos online de curta duração e de abrangência massiva, ofertados geralmente de modo gratuito, onde é possível obter certificação fornecida por universidades e instituições de ensino. Neste momento de pandemia do Covid-19, que impossibilita a realização dos cursos presenciais, é uma alternativa para aqueles que precisam continuar seu desenvolvimento e de forma gratuita.

Este estudo contribui com a temática sobre MOOCs no Brasil ao relacionar as características de oferta em algumas instituições. Buscou-se analisar as principais plataformas brasileiras disponíveis, porém não houve acesso a todos os dados para se fazer uma avaliação da qualidade dos cursos. Houve a solicitação, por e-mail, às plataformas sobre disponibilização de dados referentes à quantidade de alunos e avaliações realizadas, entretanto, não foram atendidas. Outra limitação do estudo é que não atingiu a totalidade de instituições que ofertam cursos no Brasil.

Apesar da limitação de coleta de dados a algumas instituições, nota-se uma variedade de cursos promovidos que possibilitam aos interessados uma diversidade de temas e período de duração, com novas possibilidades e novos modelos de aprendizagem a serem difundidos e explorados.

\section{REFERÊNCIAS}

BARDIN, L. Análise de conteúdo. Lisboa: Edições 70, 1979.

BARIN, C. S.; BASTOS, F. P. Problematização dos MOOC na atualidade: potencialidades e Desafios. Novas Tecnologias na Educação, v.11, n.3,p. 1-10, 2013.

BRASIL. Decreto $\mathrm{n}^{\circ}$ 9.057, de 25 de maio de 2017. Regulamenta o art. 80 da Lei $\mathrm{n}^{\circ}$ 9.394, de 20 de dezembro de 1996 , que estabelece as diretrizes e bases da educação nacional. Presidência da República, Brasília, DF, 2017. Disponível em: http://www.planalto.gov.br/ccivil_03/_ato20152018/2017/decreto/d9057.htm . Acesso em: 16 abr. 2020.

BRASIL. Lei $\mathrm{n}^{\circ}$ 13.979, de 6 de fevereiro de 2020. Dispõe sobre as medidas para enfrentamento da emergência de saúde pública de importância internacional decorrente do coronavírus responsável pelo surto de 2019. Presidência da República, Brasília, DF, 2020. Disponível em: http://www.planalto.gov.br/ccivil_03/_ato2019-2022/2020/lei/113979.htm . Acesso em: 21 abr. 2020. 
CARMO, E. A.; ARAUJO, C. L.; ABBAD, G. S.; MENEZES, P. P. M. O que se diz sobre os MOOCs? A produção científica brasileira sobre os Massive Open On-line Courses nos últimos 10 anos. RISTI [online]. 2019, n.33, pp.1-15. ISSN 1646-9895. Disponível em: http://dx.doi.org/10.17013/risti.33.1-15. Acesso em: 16 abr. 2020.

DAL FORNO, J. P.; KNOLL, G. F. Os MOOCS no mundo: um levantamento de cursos online abertos massivos. Nuances: estudos sobre Educação, Presidente Prudente-SP, v. 24, n. 3, p. 178-194, set./dez. 2013.

MOURA, V. F.; SOUZA, C. A. Características Disruptivas dos Massive Open Online Courses (MOOCs): Uma Análise Exploratória no Ensino Superior Brasileiro. Teoria e Prática em Administração (TPA), v. 7, n. 2, p. 102-127, 2017. Disponível em: https://doi.org/10.21714/2238-104X2017v7i2-33103. Acesso em: 16 abr. 2020.

EDX. Pesquisar cursos e programas. 2021. Disponível em: https://www.edX.org/search Acesso em: 02 maio 2021.

FASSBINDER, A.; DELAMARO, M. E.; BARBOSA, E. F. Construção e uso de MOOCs: uma revisão sistemática. In: BRAZILIAN SYMPOSIUM ON COMPUTERS IN EDUCATION, 25. (Simpósio Brasileiro de Informática na Educação-SBIE). Anais [...], 2014. p. 332. Disponível em: http://dx.doi.org/10.5753/cbie.sbie.2014.332 . Acesso em: 16 abr. 2020.

FGV- Fundação Getúlio Vargas. Mercado de Trabalho: Sob impacto do COVID-19, indicador sinaliza ritmo forte da taxa de desemprego. Publicado em: 08 abr. 2020. Disponível em: https://portal.fgv.br/noticias/mercado-trabalho-sob-impacto-covid-19-indicador-sinalizaritmo-forte-taxa-desemprego . Acesso em: 15 maio 2020.

G1. Novo coronavírus é emergência de saúde internacional, declara OMS. Publicado em: 30 jan. 2020 16h43. Disponível em: https://g1.globo.com/ciencia-e-saude/noticia/2020/01/30/novocoronavirus-e-emergencia-de-saude-internacional-declara-oms.ghtml . Acesso em: 06 maio 2020.

MACHADO, K. G. W. Os MOOCs Como Possibilidade Para Internacionalização Da Educação Superior Em Casa. Dissertação (Mestrado) Ao Programa De Pós-Graduação Da PUCRS, 2019. Disponível em: http://tede2.pucrs.br/tede2/handle/tede/8472 . Acesso em: 30 jun. 2020.

MARTINS, T. B.; LEITE, M. S.; PAVANY M.; RAMOS, A. M. Cursos online abertos e massivo no Brasil no contexto da internacionalização da educação superior. Revista Inter. Educ.

Sup.Campinas, SPv.3n. 3p. 604-623set./dez. 2017.

MELO, M. S. S.; OLIVEIRA, E. A. A. Q. Educação a Distância: Desafios da modalidade para uma Educação 4.0. Revista Interdisciplinar de Tecnologias e Educação, [S.1.], v. 5, n. 1, p. 15, nov. 2019. ISSN 2447-5955. Disponível em:

http://rinte.ifsp.edu.br/index.php/RInTE/article/view/473 . Acesso em: 16 abr. 2020.

MOTA, R.; SANTOS, A. I. MOOC, uma revolução em curso. Disponível em: https://aisantos.wordpress.com/redirect?url=http\%3A\%2F\%2Fwww\%2Ejornaldaciencia\%2Eorg \%2Ebr\%2FDetalhe\%2Ejsp\% . Acesso em: 21 abr. 2020. 
MOURÃO, L.; ABBAD, G. S.; ZERBINI, T. Avaliação da efetividade e dos preditores de um treinamento a distância em uma instituição bancária de grande porte. Rev. Adm. (São Paulo), São Paulo, v. 49, n. 3, p. 534-548, Sept. 2014 . Available from

http://www.scielo.br/scielo.php?script=sci_arttext\&pid=S0080-

21072014000300008\&lng=en\&nrm=iso . Acesso em: 30 abr. 2020.

OPENUPED. Cursos. 2021. Disponível em: https://www.openuped.eu/courses . Acesso em: 02 maio 2021.

PIMENTEL, A. O método de análise documental: o uso para uma pesquisa historiográfica.

Cadernos de Pesquisa. 2001, n.114, pp.179-195. Disponível em:

https://www.scielo.br/pdf/cp/n114/a08n114.pdf . Acesso em: 30 jun. de 2020.

RAMOS, D. K.; RIBEIRO, F. L. Por uma gestão mais democrática na educação: contribuições de uma formação a distância para atuação profissional de seus egressos. Avaliação (Campinas), Sorocaba, v. 24, n. 3, p. 766-784, Dec. 2019. Disponível em: https://www.scielo.br/scielo.php?script=sci_arttext\&pid=S141440772019000300766\&lng=en\&nrm=iso . Acesso em: 16 abr. 2020.

SOUSA, Alline Alves de; ZERBINI, Thaís. Learning predictors in a distance program: a study with public healthcare providers. Trends in Psychology, v. 27, n. 1, p. 11-23, 2019. 